\title{
Study on the Selection Method of PPP Mode in the
}

\section{Domain of Public Infrastructure}

\author{
Ming Chang \\ Tianjin Polytechnic University, Tianjin 300160, China \\ E-mail: changming124@163.com \\ Weihua Liu \\ Tianjin Polytechnic University, Tianjin 300160, China
}

\begin{abstract}
In this article, we list and compare specific investment and financing modes in the domain of public infrastructure, put forward main factors which influence the mode selection, establish the index system for the mode selection, and finally bring the method of fuzzy comprehensive evaluation into the specific mode selection under the concept of PPP (Public Private Partnerships) to strive for the quantification of the qualitative analysis.
\end{abstract}

Keywords: PPP, Mode selection, Fuzzy comprehensive evaluation

The infrastructure is the establishment or institution which can directly provide common conditions and public services for the production department and people living. The infrastructure has many characters such as antecedence, foundation, non-trade, impartibility and so on, and it possesses three functions including improving economic development, changing social and economic structure, and increasing employment and enhancing people living standard in the process of economic development and modernization. However, limited financing ability always perplexes pubic institutions which construct and manage infrastructures. Therefore, to improve the marketization of the investment and financing in the domain of public infrastructure is the important content to deepen the investment system reform of China. The introduction of PPP mode can not only help the government to solve problems existing in the domain of the public infrastructure, but also is propitious to the development of the private economy.

\section{The investment and financing mode of PPP}

Through many years' practice and theoretic developments, PPP produces many specific modes, and some modes also produce some aberrance forms. For the specific investment and financing mode, according to the degree that two cooperators participate in the project, the time of the cooperative term, and the ownership of the project, we can divide the mode into three types including the outsourcing type, the franchise type and the privatization type. Generally, the project of the outsourcing type is invested by the public departments, and the private departments contract one function or several functions (such as service contract and O\&M) in the whole project, or take on the construction task (such as DB) of the infrastructure according to the agreement. In the project of the outsourcing type, the degree that the private department participates in the project is limited, so they take on few tasks, and the cooperative term is relative short. But in the project of the privatization type, the investment, construction and management of the project all are assumed by the private department (such as BOO), and the ownership of the project also belongs to the private department, and the public department only takes on corresponding supervisory responsibilities. The project of the franchise type is between the outsourcing type and the privatization type, and both cooperators take on project risks together and share project incomes, and the ownership of the project belongs to the public department.

The privatization master E.S. Sawas showed main types of PPP by means of the series form which is seen in Table 1 . The most upper mode on this series is the perfect public mode, and the lowest mode is the perfect private mode. In this article, we will combine these two sorts of classification method.

From Table 1, we can see that the public degree from upper to lower is lower and lower and the private degree is higher and higher, and the upper arrowhead denotes the perfect public evaluation 1.0, and the lower arrowhead denotes the perfect private evaluation 0. From upper to lower, the evaluation is smaller and smaller, which shows the public degree decreases and the private degree increases, and the table lists 11 representative specific modes including familiar LBO, BTO, BOT and BBO.

\section{The application of the fuzzy comprehensive evaluation method in the PPP investment and financing mode selection}

\subsection{Influencing factors of PPP investment and financing mode selection}

The mode selection of PPP investment and financing is influenced by many factors, and the government of the 100 
infrastructure and the private cooperator are the most primary factors. Specifically speaking, the goods attribute of the public infrastructure, the conscientiousness and concepts of the government and the private cooperator's object have decisive functions in the model selection of the specific investment and financing of the public infrastructure. Whether a certain public infrastructure project adopts which investment and financing mode should be decided by the comprehensive compare of these influencing factors.

\subsubsection{Goods attribute of public infrastructure}

Non-competition is that the increase of customer can not bring the increase of production cost. In another words, the non-competition of public goods means the social marginal cost induced by the increase of customer is zero, and for the consumption of public goods, every one can obtain same benefit without interference. Taking a broadcaster as an example, the broadcast possesses typical character of non-competition, and A's listening doesn't foreclose B's listening.

Non-exclusion means that once the public goods is provided to some people, so others cannot be stopped profiting, or at least expensive costs should be expended to stop others profit. Taking the national defense as an example, if the national defense is provided in a country, it is impossible to exclude the national defense protection of any people who lives in this country.

Pure public goods possess complete characters of non-competition and non-exclusion. But in actual economy, the specific attribute of the product is complex, and many goods are between the public goods and the private goods, which can be called as quasi-public goods. The quasi-public goods can be divided into the crowded public goods and the public goods with exclusive price. The crowded public goods mean that after more customers are absorbed, overabundance or crowded people will decrease public goods that present customers profit. When the crowded point is achieved, the marginal cost of one extra customer is not zero. For example, the crowded road which increases one user will decrease present users' profits, because it will make the traffic slow and increase the risk of traffic accident. The public goods consumption with exclusive price has the character of non-competition, but it can exclude others from the technology. For example, these products such as school, hospital and public establishment can be priced, but their supplies will induce the character of positive exterior.

To sum up, the social product takes the competition and exclusion as standards, which can be divided into two sorts including pure public goods, pure private goods, crowded public goods, and the public goods with exclusive price. Differences among four sorts are showed in Table 2.

Obviously, because degrees of competition and exclusion are different, so the investment and financing modes of public infrastructure with different characteristics should have differences. To general quasi-public goods, because their degrees of non-exclusion and non-competition are very high, so they will induce deficient supply in the free competitive market, and to these public projects, the supply of the government is the best choice. However, the service outsourcing with high public degree can be selected, and the service of this type of establishment can be contracted with professional company to fully utilize its advanced technology or management experience and enhance the service level of the public establishment. To the club goods which degree of non-competition is higher than its degree of non-exclusion (such as toll road), LBO or BTO with middle public degree are the effective selection for this type of public infrastructure. But to crowded goods (such as urban road, public sewerage system and so on), because of their strong non-exclusive character and obvious competition of consumption, they are more close to private goods, so the BBO mode with high private degree can be adopted.

\subsubsection{Consciousnesses and concepts of the government}

As a sort of theory or a sort of mature management idea, the urban management was first put forward in western countries with early and quick urbanization course. The urban management is to take city as the largest state-owned capital, exert the means of market economy to centralize, recombine and operate natural capitals (such as soil), human function capitals (such as road and bridge) and relative extended capitals (such as naming rights of bridge and road), implement the marketization way of urban construction which depends the city to maintain, construct and improve city, realize the new concept and new mode of urban construction that the city can improve, accumulate and increase itself under the condition that the government gradually decreases investments. Dalian, Qingdao, Zhuhai and Sanya are those typical cities. If the government can develop and innovate in advanced concept with urban management, it can enhance the utilization degree of private capital and decrease the system bulwark in the infrastructure industry in the aspects of public infrastructure construction and service supply, and make private departments can not only enter these domains, but gradually develop their activity range and participation degree, so the financing mode with high private degree can be realized. By contraries, if the government can not liberate its idea, still is tied in those traditional concepts, and dares not to use private capitals, so it can only adopt the financing mode with high public degree. 


\subsubsection{Private cooperator's object}

Because various investment and financing modes of PPP have obvious differences in aspects of project term, risk distribution, income obtainment and so on, different anticipant objects of private departments will also influence their modes and degrees to participate in the project. For example, the cooperator which emphasizes short income and has advantages of technology and management may more favor modes of management contract, service agreement or "turn-key", and may worry BOT and BOO which have long project term and have not obvious short income. In addition, because the project of public infrastructure has high requirement for the capital, the scale of the private capital will influence its participation degree.

To sum up, under the mode of PPP, the investment and financing mode selection of PPP is decided by many factors. Therefore, we should comprehensively consider these influencing factors, compare various cooperative modes, and select more reasonable investment and financing mode to achieve both cooperators' anticipant objects.

\subsection{The method of fuzzy comprehensive evaluation}

Fuzzy phenomenon means that some things have no specific attribute standard, can not be classified definitely, and present fuzzy characters. The selection of PPP investment and financing mode also has fuzzy characters. In this article, we divide selection modes into five classes from big to small evaluation, but because the standard of every class is difficult to be assumed, so this sort of classification with human subjective consciousness has fuzzy character. Factors influencing risks also have fuzzy character, so they can not be evaluated by one mark. Considering above factors, we adopt the fuzzy evaluation method to comprehensively evaluate the PPP investment and financing mode selection of infrastructure project. The analysis process of the fuzzy comprehensive evaluation method is described as follows.

(1) Confirm the evaluation index set X. $X=\left(x_{1}, x_{2}, \Lambda, x_{n}\right)$.

(2) Utilize AHP method to confirm the index weight set A. $A=\left(a_{1}, a_{2}, \Lambda, a_{n}\right)$.

(3) Confirm the evaluation set Y. $Y=\left(y_{1}, y_{2}, \Lambda, y_{n}\right)$.

(4) Confirm the standard subjection degree U. $U=\left(u_{1}, u_{2}, \Lambda, u_{m}\right)$.

(5) Establish the fuzzy estimation matrix R to the estimation object. $R=\left[\begin{array}{llll}r_{11} & r_{12} & \Lambda & r_{1 m} \\ r_{21} & r_{22} & \Lambda & r_{2 m} \\ \Lambda & \Lambda & \Lambda & \Lambda \\ r_{n 1} & r_{n 2} & \Lambda & r_{n m}\end{array}\right]$.

Where, $r_{i j}$ represents the percent that the number of the people who makes the $\mathrm{j}^{\text {th }}$ class evaluation occupies the total number of all surveyed people on the $\mathrm{i}^{\text {th }}$ index to the estimation object.

(6) Compute the fuzzy comprehensive subjection degree set B.

(7) Implement second fuzzy comprehensive evaluation according to the estimation result of the first factor.

(8) Compute the comprehensive subjection degree, $\mathrm{P}=B \cdot U^{T}$.

The comprehensive subjection degree is the total estimation mark to the estimation object, and according to this mark, we can objectively evaluate many estimation objects.

\subsection{Application case}

Taking the construction of certain urban subway project, we actually apply this evaluation mode, invite relative experts to mark this project, comprehensively consider various factors according to the computation result of the model, and select appropriate investment and financing mode.

\subsubsection{The confirmation of index weight}

Aiming at specific situation of this project, after relative experts analyze selection factors of this project, we divide index factors into three sorts including the object layer, the factor layer and the sub-factor layer according to the connotation of various index factors and mutual associated degree among indexes. The object layer is the PPP investment and financing mode selection. The factor layer includes factors from three aspects such as infrastructure, government and private cooperator. The sub-factor layer includes 8 indexes. The index system of the mode selection is shown in Figure 1.

Here, we need to confirm 3 factors and each weight of 8 indexes to evaluate the PPP mode selection. We adopt the AHP method to confirm the weight of the index. The process includes two steps. First, we ask for questionnaires from experts and consult some authorized persons' opinions for the PPP investment and financing mode selection, 
and respectively establish the factor layer and the estimation matrix of various sub-factor index layers. Second, we exert the software of Excel to figure out eigenvalues and eigenvectors of various matrixes, and obtain weights of the factor layer and various sub-factor index layers which is shown as follows (the computation process of original data is omitted).

$$
\begin{aligned}
& A=\left(a_{1}, a_{2}, a_{3}\right)=(0.42,0.28,0.3) \\
& A_{1}=\left(a_{11}, a_{12}, a_{13}, a_{14}\right)=(0.3,0.2,0.2,0.3) \\
& A_{2}=\left(a_{21}, a_{22}\right)=(0.5,0.5) \\
& A_{3}=\left(a_{31}, a_{32}\right)=(0.44,0.56)
\end{aligned}
$$

Where, $A$ represents the index weight of the factor layer (the object layer), and $A_{i}$ represents the index weight of the factor layer, $i=1,2,3$.

\subsubsection{Factor evaluation standard set}

(1) The first class fuzzy comprehensive evaluation.

After we obtain weights of all influencing factors (which have been listed in this article) by means of the AHP method, we need to confirm estimation standards of various factors. According to influencing degrees of listed factors to the PPP investment and financing mode selection in the infrastructure domain, we divide the estimation standard into five classes including very high (0.9), high (0.7), general (0.5), low (0.3), and very low (0.1).

The evaluation class set $\mathrm{Y}=$ (very high, high, general, low, very low).

Confirm the standard subjection degree of the evaluation set $\mathrm{U}=(0.9,0.7,0.5,0.3,0.1)$.

Invite the expert evaluation group to evaluate various sub-factors in the factor layer, and obtain the comprehensive evaluation class weight set of various sub-factors (the computation process of original data is omitted).

From $R_{11}=\left(r_{111}, r_{112}, r_{113}, r_{114}, r_{115}\right)$, we can obtain $R_{11}=(0,0,0,0,1)$.

Where, $R_{11}$ represents the evaluation class weight of the first index under the first factor, $r_{111}$ represents the percent that the number of the people who makes the first class evaluation (i.e. very high) occupies the total number of all surveyed people on the first index under the first factor to the estimation object. Obviously, all experts think that the private goods attribute of infrastructure should have small evaluation $\left(r_{115}=1\right)$. And only as viewed from this index, we should select the PPP investment and financing mode with low evaluation and very high private degree, such as BOT, BBO and so on.

In the same way, $R_{12}=(1,0,0,0,0), R_{13}=(0,0.1,0.56,0.34,0)$, and $R_{14}=(0,0,0.29,0.71,0)$.

Integrating evaluation classes and weights of various indexes under the first factor, we can obtain the fuzzy evaluation matrix $R_{1}=\left[\begin{array}{l}R_{11} \\ R_{12} \\ R_{13} \\ R_{14}\end{array}\right]$, and in turn compute and we can obtain the fuzzy evaluation matrix under the second factor, $R_{2}=\left[\begin{array}{l}R_{21} \\ R_{22}\end{array}\right]$.

Where, $R_{21}=(0,0.23,0.66,0.11,0)$ and $R_{22}=(0,0,0.37,0.63,0)$.

The fuzzy evaluation matrix under the third factor is $R_{3}=\left[\begin{array}{l}R_{31} \\ R_{32}\end{array}\right]$.

Where, $R_{31}=(0,0.26,0.55,0.19,0)$ and $R_{32}=(0,0,0.64,0.33,0)$.

(2) The second class fuzzy comprehensive evaluation.

The second class fuzzy comprehensive evaluation is to evaluate all factors of the factor subset, i.e. it is obtained by the computation through the formula $B_{i}=A_{i} \cdot R_{i}(\mathrm{i}=1,2,3)$.

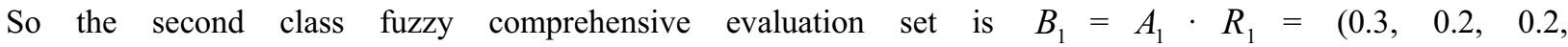


$0.3) \cdot 0.3) \cdot\left[\begin{array}{ccccc}0 & 0 & 0 & 0 & 1 \\ 1 & 0 & 0 & 0 & 0 \\ 0 & 0.1 & 0.56 & 0.34 & 0 \\ 0 & 0 & 0.29 & 0.71 & 0\end{array}\right]=(0.2,0.02,0.199,0.281,0.3)$.

In the same way, $B_{2}=A_{2} \cdot R_{2}=(0,0.115,0.515,0.37,0)$ and $B_{3}=A_{3} \cdot R_{3}=(0,0.1144,0.6004,0.2852,0)$.

(3) The third class fuzzy comprehensive evaluation.

The third class fuzzy comprehensive evaluation is to implement comprehensive evaluation among various sorts, and

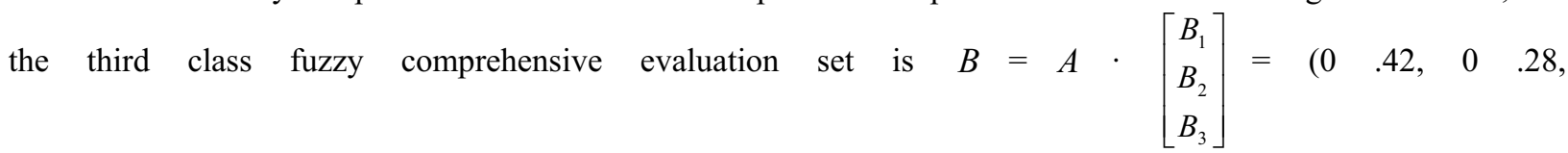

$0.3) \cdot\left[\begin{array}{ccccc}0.2 & 0.02 & 0.199 & 0.281 & 0.3 \\ 0 & 0.115 & 0.515 & 0.37 & 0 \\ 0 & 0.1144 & 0.6004 & 0.2852 & 0\end{array}\right]=(0.084,0.07492,0.4079,0.30718,0.126)$

So the comprehensive subjection degree of this project is $P=B \cdot U^{T}=0.436748$.

This subway project finances by means of PPP, and the result of the quantitative analysis using the fuzzy comprehensive evaluation method shows that it can adopt the mode with high private degree such as LBO, BTO, and even BOT. The final mode selection should certainly comprehensively consider other factors, but this method can quantify qualitative selection and offer scientific references to select investment and financing mode for the government and the private cooperator. And this article still has some advantages in the establishment of the index system which needs to be further improved.

\section{References}

Chen, Jingwu, Yuan, Zhixue, Huanggeng \& Liya. (2006). The Selection of Urban Infrastructure Financing Modes Based on the Public Private Partnership. Construction Economy. No.5.

Chen, Yuemei \& Xu, Zhenyu. (2006). The Selection of Urban Infrastructure Financing Modes Based on the Public Private Partnership. Construction Economy. No.12.

Xiongbo. (2005). PPP Mode: the New Mode that Private Economy Participates in the Public Utility. China Urban Economy. No.1.

Zhang, Lihong, Wang, Haiqin \& Wangdong. (2006). PPP Mechanism and Urban Infrastructure. Environment and Sustainable Development. No.5. 
Table 1. PPP series

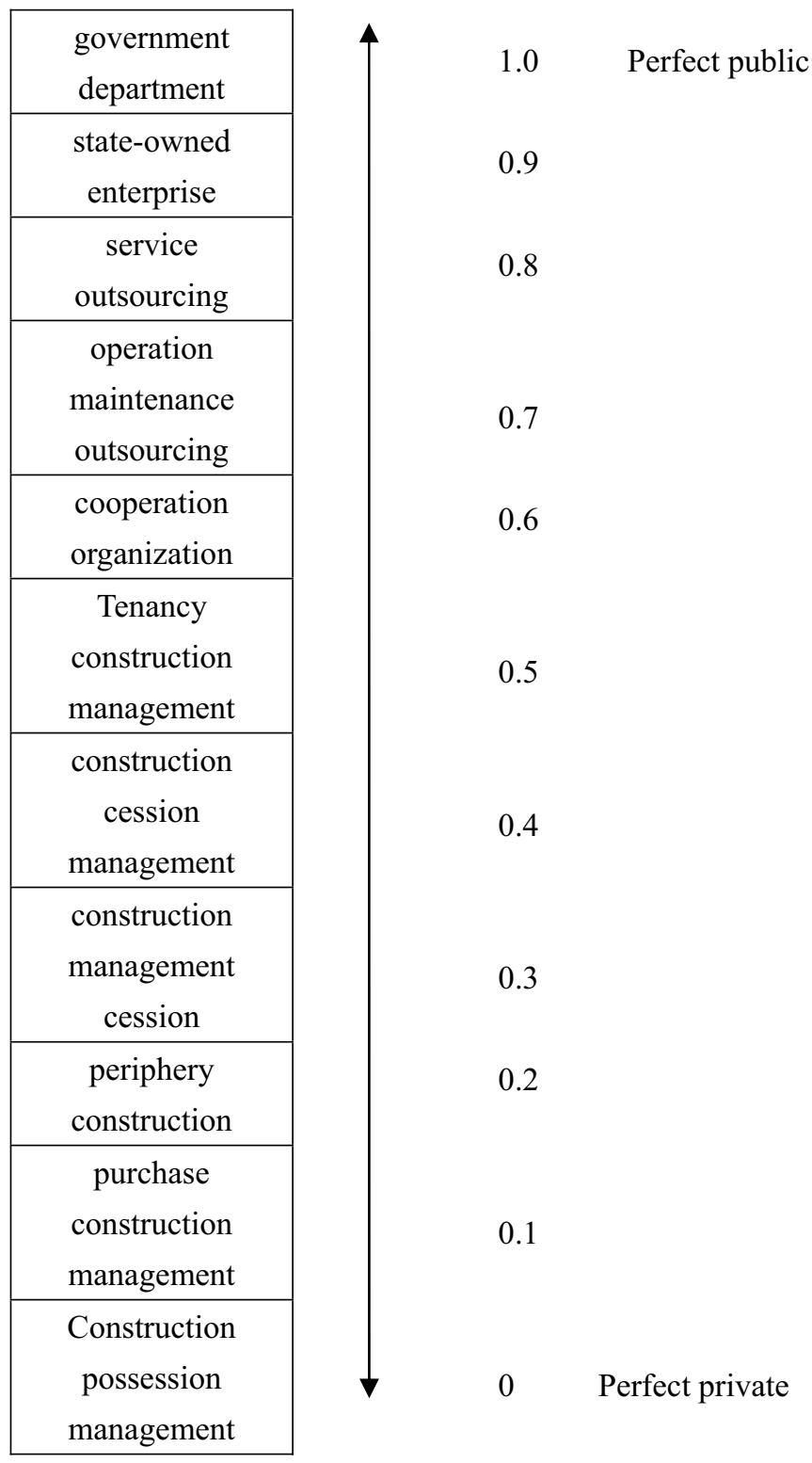


Table 2. Characteristics of four sorts of goods and their supply modes

\begin{tabular}{|c|c|c|c|}
\hline Goods type & Basic characteristic & Supply mode & example \\
\hline $\begin{array}{l}\text { Pure private } \\
\text { goods }\end{array}$ & $\begin{array}{l}\text { Consumption alone } \\
\text { Without exterior character } \\
\text { Exclusivity of low cost }\end{array}$ & $\begin{array}{l}\text { Supply by the market } \\
\text { Charge from consumers }\end{array}$ & $\begin{array}{l}\text { Foods } \\
\text { Costume } \\
\text { Auto }\end{array}$ \\
\hline $\begin{array}{l}\text { Public goods } \\
\text { with } \\
\text { exclusive } \\
\text { price (club } \\
\text { goods) }\end{array}$ & $\begin{array}{l}\text { Consumption alone } \\
\text { With exterior income when } \\
\text { it is produced or consumed } \\
\text { Exclusivity of low cost }\end{array}$ & $\begin{array}{l}\text { Supply by the government or } \\
\text { the market financed by the } \\
\text { government }\end{array}$ & $\begin{array}{l}\text { Toll road } \\
\text { Hospital } \\
\text { Post and } \\
\text { telecom }\end{array}$ \\
\hline $\begin{array}{l}\text { Crowded } \\
\text { public goods }\end{array}$ & $\begin{array}{l}\text { The income of collective } \\
\text { consumption is decided by } \\
\text { the crowded degree } \\
\text { Possible exclusivity }\end{array}$ & $\begin{array}{l}\text { Supply by the government or } \\
\text { the market financed by the } \\
\text { government }\end{array}$ & $\begin{array}{l}\text { Highway and } \\
\text { bridge } \\
\text { Comfort station }\end{array}$ \\
\hline $\begin{array}{l}\text { Pure public } \\
\text { goods }\end{array}$ & $\begin{array}{l}\text { The income of collective } \\
\text { consumption is not decided } \\
\text { by the crowded degree } \\
\text { Exclusivity of high cost }\end{array}$ & $\begin{array}{l}\text { Supply by the government } \\
\text { Government investment }\end{array}$ & $\begin{array}{l}\text { National } \\
\text { defense } \\
\text { Common } \\
\text { Highway } \\
\text { Lighthouse }\end{array}$ \\
\hline
\end{tabular}

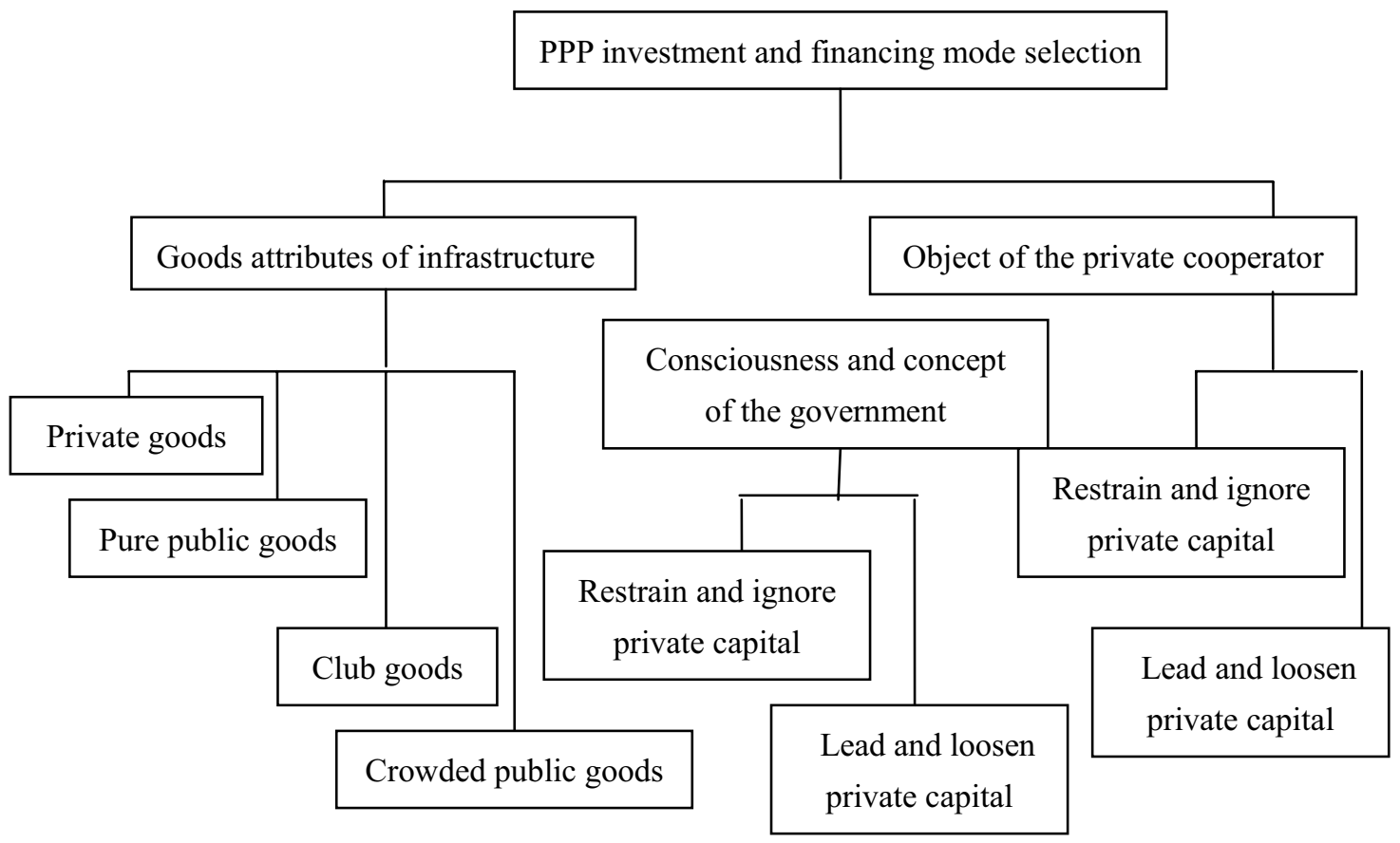

Figure 1. The Index System of PPP Mode Selection 